\title{
EFFECTS OF MINOR CHEMISTRY VARIATIONS ON THE STRUCTURAL AND MECHANICAL BEHAVIOUR OF ALLOY 718
}

\author{
K.K. Sharma and K. Muraleedharan \\ Defence Metallurgical Research Laboratory, Hyderabad-500 058, India
}

Three chemistry variants of alloy 718 were prepared at laboratory scale by vacuum induction melting followed by vacuum arc remelting. The first alloy contained $2 \%$ cobalt and iron was reduced by a similar amount. In the second alloy variant $2 \%$ cobalt was added at the expense of nickel and the third alloy was modified by adding $0.02 \%$ cerium.. The billets of the modified alloys and also the standard alloy were processed to prepare $12.5 \mathrm{~mm}$ diameter bars that were subjected to conventional heat treatment. Tensile and stress rupture properties of the four alloys were evaluated under different conditions. Replacement of iron by cobalt did not produce any noticeable effect on the tensile and stress rupture properties and reduction in nickel was also found to produce marginal effect on these properties. The cerium modified alloy, however, showed significant increase in the stress rupture properties. The reasons for this mechanical behaviour have been examined with the help of transmission electron microscopy and are discussed. 


\section{Introduction}

Among many superalloys that are used in modern gas turbine aero engines, Inconel 718 occupies a very prominent position. Exceptionally good formability, excellent weldability and high resistance to surface degradation are some of the important characteristics which have made this alloy universally acceptable for structural applications at intermediate temperatures up to $650^{\circ} \mathrm{C}[1,2]$.

Like most nickel base superalloys, Inconel 718 also owes its strength to precipitation hardening and the major strengthening phase is $\gamma^{\prime \prime}$, which has an ordered body-centered-tetragonal $\mathrm{DO}_{22}$ crystal structure and stoichiometric composition of $\mathrm{Ni}_{3}(\mathrm{Nb}, \mathrm{Ti}, \mathrm{Al})$. Besides uniformly distributed carbides of $\mathrm{MC}$ type, small amount of $\gamma^{\prime}$ based on $\mathrm{Ni}_{3} \mathrm{Al}$ is also present in alloy 718. However, contribution of $\gamma^{\prime}$, as a strengthener is believed to be much less as compared to that of the $\gamma^{\prime \prime}$. Whereas the $\gamma^{\prime \prime}$ particles are disc shaped, the $\gamma^{\prime}$ particles are spheroidal and of much smaller diameter. $\gamma^{\prime \prime}$ is a metastable phase and over prolonged exposures at temperatures above $650^{\circ} \mathrm{C}$, it tends to form a stable phase, $\delta$, which has an incoherent, orthorhombic crystal structure. Being lath shaped and having a tendency to precipitate at the grain boundaries by a cellular reaction, the $\delta$ phase is believed to have an adverse effect on the alloy ductility. However, $\delta$ phase helps in preventing grain growth during various stages of processing and if present in moderate amounts, it is understood to be beneficial $[3,4]$.

Since the introduction of the alloy 718 in Sixties by Eiselstein, long time stability of its phases, i.e., $\gamma^{\prime}$ and $\gamma^{\prime \prime}$, has always been a major concern and has led to extensive studies on various metallurgical aspects the world over. Several chemistry modifications have been attempted and many heat treatment schedules have been investigated to improve its performance $[2,5,6]$. Several investigators have also addressed alloy cleanliness by introducing double and triple refining techniques [7]. Role of minor elements such as magnesium, boron, zirconium and rare earth elements in improving the high temperature strength of 718 has also been studied $[8,9,10]$. Cerium is found to be useful if its content is limited to less than 0.025 weight $\%$ [8].

Cobalt is generally present in most nickel base superalloys as it is believed to strengthen the matrix besides increasing the solvus of $\gamma^{\prime}$, thereby increasing the high temperature strength of the alloys [11]. Following cobalt scarcity crisis in Seventies, its role was further examined in several superalloys [12], particularly on the hot workability where it is not found to be much useful [13]. However, the role of cobalt in alloy 718 has not received much attention. The present investigation, forming part of a turbine disc material development programme, is, therefore, aimed at understanding the effect of cobalt on the high temperature behaviour of alloy 718 . We also include the results of a study carried out to examine the scavenging effect of cerium in Alloy 718 by Auger electron spectroscopy (AES).

\section{Experimental}

Four chemistry variants of alloy 718 were prepared by vacuum induction melting (VIM) followed by vacuum arc remelting (VAR) to produce $75 \mathrm{~mm}$ diameter and $300 \mathrm{~mm}$ long ingots. Care was taken to ensure that melting and refining parameters 
are consistent in all the four VIM heats. These VAR ingots were homogenized at $1150^{\circ} \mathrm{C}$ for $24 \mathrm{hrs}$ and slices of appropriate thickness were cut off from their top as well as bottom faces. The cylindrical surfaces of ingots were also machined to remove any surface imperfections. Samples for chemical analysis were taken from both top and bottom faces of the ingots. The chemical compositions of the four VAR ingots are given in table 1.

Table I. Chemical composition of experimental alloys based on alloy 718 , weight $\%$.

\begin{tabular}{|l|c|c|c|c|}
\hline Element & Alloy 1 & Alloy 2 & Alloy 3 & Alloy 4 \\
\hline Carbon & 0.040 & 0.039 & 0.037 & 0.042 \\
\hline Chromium & 18.05 & 18.11 & 18.25 & 18.01 \\
\hline Iron & 18.20 & 16.15 & 18.01 & 17.95 \\
\hline Niobium & 5.25 & 5.22 & 5.20 & 5.18 \\
\hline Titanium & 0.86 & 0.85 & 0.88 & 0.87 \\
\hline Molybdenum & 3.12 & 3.15 & 3.08 & 3.08 \\
\hline Aluminium & 0.67 & 0.68 & 0.69 & 0.71 \\
\hline Cobalt & 0.1 & 2.01 & 2.12 & 0.12 \\
\hline Sulphur & $<0.01$ & $<0.01$ & $<0.01$ & $<0.01$ \\
\hline Boron & $<0.01$ & $<0.01$ & $<0.01$ & $<0.01$ \\
\hline Zirconium & $<0.01$ & $<0.01$ & $<0.01$ & $<0.01$ \\
\hline Cerium & - & - & - & 0.015 \\
\hline Nickel & 53.65 & 53.70 & 51.82 & 53.85 \\
\hline
\end{tabular}

All the four ingots were soaked at $1180^{\circ} \mathrm{C}$ for 4 hours before forging them under a $1000 \mathrm{~kg}$ hammer to form $40 \mathrm{~mm}$ square billets. The forged billets were machined to remove any surface cracks or irregularities and then hot rolled to produce $12.5 \mathrm{~mm}$ diameter bars. These bars were solution treated at $955^{\circ} \mathrm{C}$ for 1 hour followed by water quenching. The aging treatment consisted of heating the bars at $720^{\circ} \mathrm{C}$ for 8 hours, furnace cooling to $620^{\circ} \mathrm{C}$, holding at $620^{\circ} \mathrm{C}$ for 4 hours and then air-cooling. The heattreated bars were machined to prepare specimens for both tensile and stress rupture tests in accordance with the ASTM procedures. Some of the heat-treated bars were also machined to make the specimens for in-situ fracture examination by Auger electron spectroscopy (AES). Tensile tests were carried out at room temperature and $650^{\circ} \mathrm{C}$. Stress rupture tests were performed at $650^{\circ} \mathrm{C}$ with a constant load of $690 \mathrm{MPa}$. Microstructural examination of the specimens extracted from the grips of the stress rupture specimens after tests was conducted by optical as well as scanning electron microscopy. Kallings reagent was used to reveal the microstructures. Thin foils of these specimens were prepared by twinjet electro-polishing in an electrolyte containing $78 \%$ methanol, $10 \%$ lactic acid, $7 \%$ sulphuric acid, $3 \%$ nitric acid at $-30^{\circ} \mathrm{C}$ and 12 volts. These foils were examined using Philips EM-430T transmission electron microscope.

Auger electron spectroscopy was carried out on the in-situ fractured $3.6 \mathrm{~mm}$ diameter notch specimens using a Physical Electronics-545 scanning Auger microprobe (SAM). The fractured surfaces were analysed before and after argon ion sputtering up to a surface of $80 \mathrm{~nm}$ at an etching rate of $2 \mathrm{~nm}$ per minute and Auger spectra obtained after every $10 \mathrm{~nm}$ sputtering intervals. The peak-to-peak height ratios for several elements with respect to nickel were recorded against the sputtered depths. 


\section{Results and Discussion}

Tensile and Stress - Rupture Properties

Table II Room Temperature tensile property of standard and modified alloy.

\begin{tabular}{|c|c|c|c|}
\hline $\begin{array}{c}\text { Alloy } \\
\text { Designation }\end{array}$ & $\begin{array}{c}\text { Ultimate Tensile } \\
\text { Strength, Mpa }\end{array}$ & $\begin{array}{c}0.2 \% \text { Yield strength, } \\
\text { Mpa }\end{array}$ & Elongation, \% \\
\hline Alloy 1 & 1338 & 1075 & 26 \\
\hline Alloy 2 & 1328 & 1068 & 26 \\
\hline Alloy 3 & 1295 & 1042 & 27 \\
\hline Alloy 4 & 1357 & 1085 & 24 \\
\hline
\end{tabular}

The room temperature tensile properties of the standard alloy and three modified alloys are given in Table 2. It is seen that the tensile properties are generally similar for all these alloys. However, alloy 3 , which has $2 \%$ cobalt and lower nickel, shows a slight drop in both the yield strength and tensile strength values in comparison with other alloys. Since elongation values are also similar, minor drop in the yield and tensile strengths for the alloy 3 is not considered significant keeping in view the fact that these are average values of three tests carried out. Some scatter in the properties of superalloys is always expected.

Table III Tensile Properties of experimental alloys at $650^{\circ} \mathrm{C}$

\begin{tabular}{|c|c|c|c|}
\hline $\begin{array}{c}\text { Alloy } \\
\text { Designation }\end{array}$ & $\begin{array}{c}\text { Ultimate Tensile } \\
\text { Strength, Mpa }\end{array}$ & $\begin{array}{c}0.2 \% \text { Yield } \\
\text { Strength, Mpa }\end{array}$ & Elongation, \% \\
\hline Alloy 1 & 997 & 888 & 9 \\
\hline Alloy 2 & 1023 & 956 & 7 \\
\hline Alloy 3 & 1019 & 897 & 8 \\
\hline Alloy 4 & 1105 & 1010 & 10 \\
\hline
\end{tabular}

Table 3 lists the average tensile properties of these alloys at $650^{\circ} \mathrm{C}$. Whereas these properties are comparable in case of alloys 1,2 and 3, substantial improvement in both yield strength and tensile strength for alloy 4 is noticeable. The elongation has also shown some improvement. The tested specimens of all these four alloys were also subjected to fractographic examination but showed similar behaviour (not presented here).

Table IV Stress Rupture properties of experimental alloys at $650^{\circ} \mathrm{C} / 690 \mathrm{Mpa}$

\begin{tabular}{|c|c|c|}
\hline Alloy Designation & S-R Life, Hours & Elongation, $\%$ \\
\hline Alloy 1 & 98.8 & 9.7 \\
\hline Alloy 2 & 136.0 & 10.6 \\
\hline Alloy 3 & 106.5 & 10.5 \\
\hline Alloy 4 & 318.0 & 18.5 \\
\hline
\end{tabular}

Results of stress rupture tests carried out on these four alloys are presented in Table 4. As compared to alloys 1 and 3, alloy 2 showed a small improvement but alloy 4 demonstrated very high stress rupture life. 


\section{$\underline{\text { Microstructural Evaluation }}$}

Microstructures of longitudinal sections of these tested specimens are given in Fig. 1 and do not show a noticeable difference in their grain size except that alloy 3
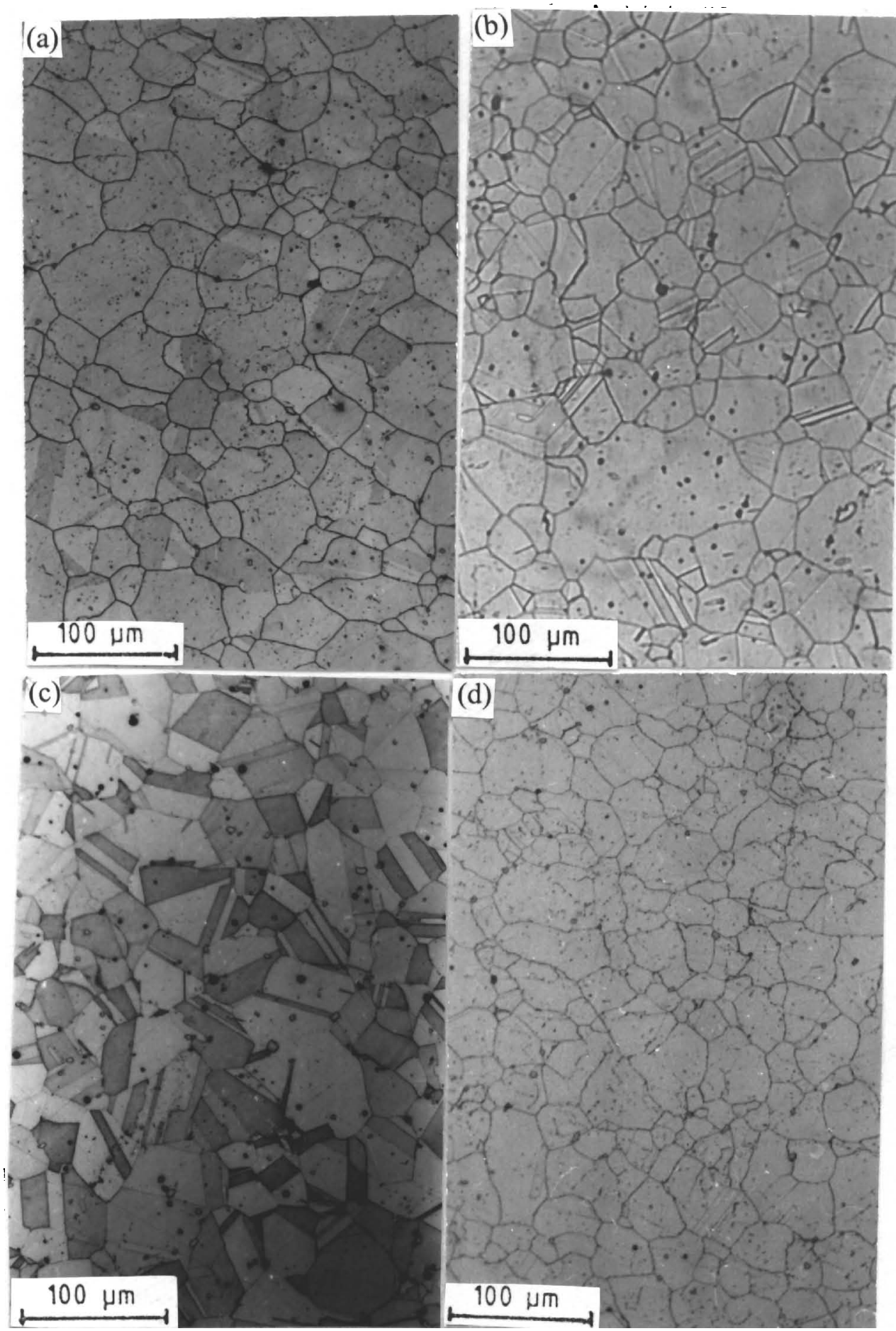

Fig. 1 Microstructures of experimental alloys based on alloy 718 , (a)alloy 1, (b) alloy 2, (c) alloy 3, (d) alloy 4 
showed a large amount of twinned grains and alloy 4 had a relatively cleaner microstructure. This cleanliness nay be attributed to the effect of cerium in removing sulphur and is also believed to be responsible for a significantly high stress rupture life of alloy 4 (Table 4 ). A closer examination of alloy 4 by scanning electron microscopy showed the onset of $\delta$ phase precipitation as manifested by the presence of discrete particles and as confirmed by EDAX analysis (Fig 2). As delta phase was not noticed in alloy 2 even during scanning electron microscopy, it is believed that its presence in alloy 4 is due to prolonged exposure at $650^{\circ} \mathrm{C}$ during the stress rupture test. Delta phase was also not noticed in any of these four alloys after forging or even after the heat treatment.

As microstructural examination of the stress rupture tested specimens did not clearly reveal the reasons for the improvement in the stress rupture lives of alloy 2 and 4 , it was decided to conduct transmission electron microscopy on these specimens.

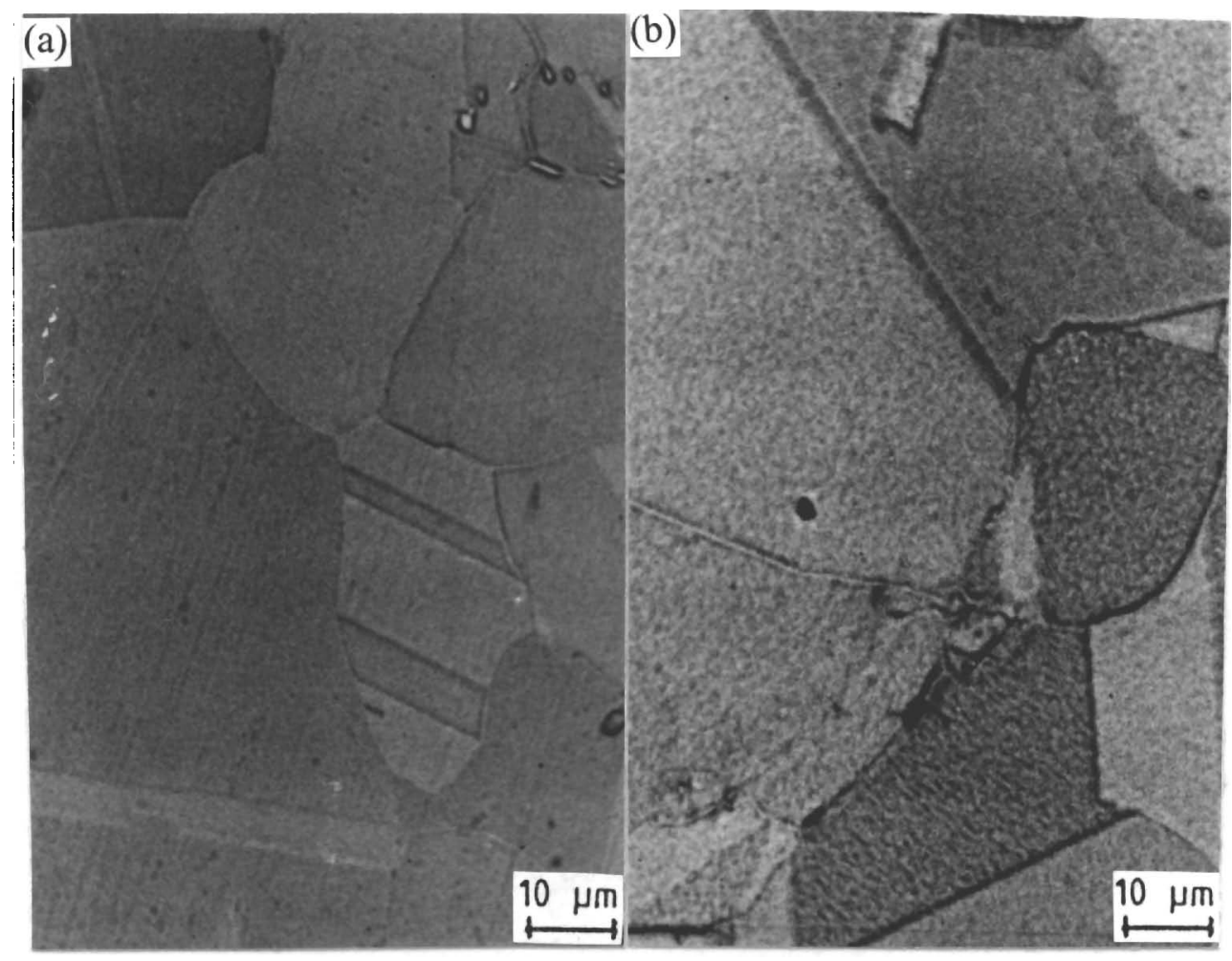

Fig. 2 Scanning Electron micrographs of (a) alloy 4 and (b) alloy 2

\section{Transmission Electron Microscopy}

Transmission electron micrographs of alloy 4 , which gave a high stress-rupture life, are presented in Fig 3. These show the presence of $\gamma^{\prime}$ and $\gamma^{\prime \prime}$ particles. The delta phase could not be detected but some areas appeared to have a morphology like that of the $\delta$ particles. Since electron diffraction pattern could not be obtained, it is beieved that these are areas of $\delta$ phase particles that might have dissolved or dropped off during the electropolishing of thin foil, as is evident from Fig 3(b). 

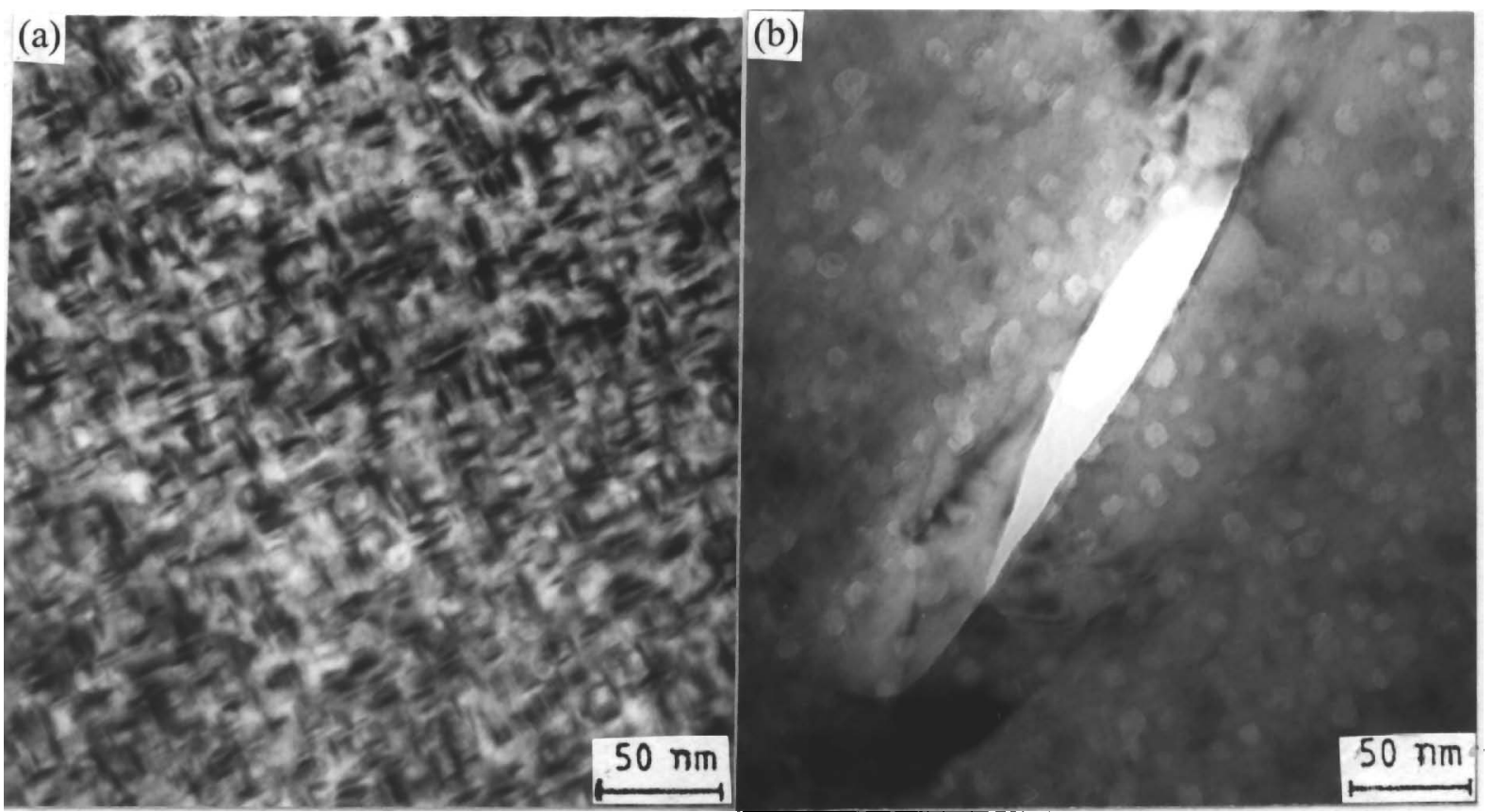

Fig. 3 Transmission electron micrographs of alloy 4 showing (a) $\gamma^{\prime \prime}$ precipitates (b) morphology and size of $\delta$ phase particle that could have fallen out during electropolishing

Fig. 4 shows the transmission electron micrographs of alloy 2 specimen which failed after giving a stress rupture life of 136 hours. Dimensions of both $\gamma^{\prime}$ and $\gamma^{\prime \prime}$ particles for this alloy were found to be much lower than those in the alloy 4 as shown in Table 5.

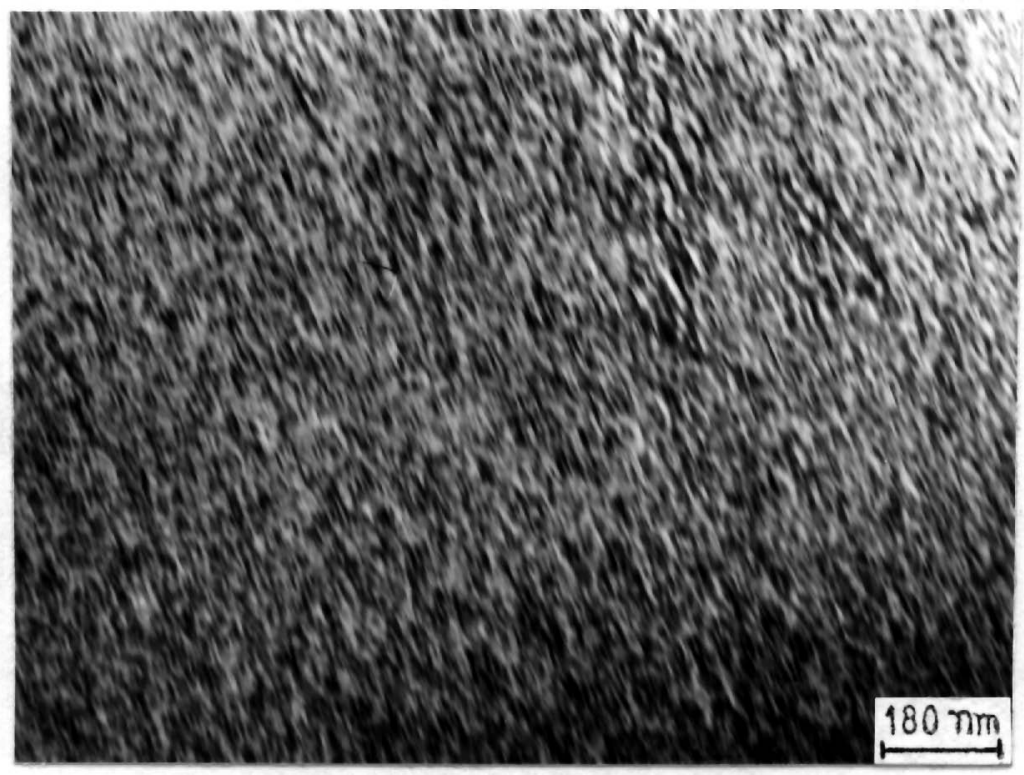

Fig.4. Transmission electron micrographs of alloy 2 showing the presence of $\gamma^{\prime}$ and $\gamma^{\prime \prime}$ 
Table 5, Average size of $\gamma^{\prime}$ and $\gamma^{\prime \prime}$ particles in the experimental alloy in $\mathrm{nm}$

\begin{tabular}{|c|c|c|c|}
\hline Alloy Designation & $\gamma^{\prime}$ Diameter & $\gamma^{\prime \prime}$ Diameter & $\gamma^{\prime \prime}$ Thickness \\
\hline Alloy 2 & 12 & 19 & 4 \\
\hline Alloy 4 & 17 & 42 & 3.5 \\
\hline
\end{tabular}

A large coarsening of $\gamma^{\prime \prime}$ particles in alloy 4 as compared to that in alloy 2 is believed to be due to larger exposure during stress rupture tests. It is also to be noted that the coarsening along the diameter (major axis) is more than that along the thickness (minor axis). This is in agreement with the earlier findings [14,15] which have shown that during coarsening, coalescence generally takes place along the major axis and coarsening along the minor axis does not occur.

This microstructural study consisting of optical and electron microscopy has shown that unto $2 \%$ cobalt does not appear to have any noticeable effect on the room temperature and high temperature properties, be it at the expense of nickel or iron. However, as the reasons for high stress structure life in the cerium modified alloy could not be clearly identified by electron microscopic analysis except for the coarsening of $\gamma^{\prime \prime}$ particles, it was decided to conduct Auger electron spectroscopy on the specimens of these two alloys with a view to examine certain weak surfaces that could have formed due to the segregation of sulphur.

\section{Auger Microprobe Analysis}

Results of scanning Auger microprobe analysis of the in-situ fractured specimen of alloy 1 are shown in Fig 5. Occasionally dispersed areas rich in sulphur and oxygen were detected and are shown in the Auger graphs (Fig 5b and c). Fig. 5d shows the effect of argon ion sputtering on the sulphur and oxygen enriched areas. Both $\mathrm{O} / \mathrm{Ni}$ and $\mathrm{S} / \mathrm{Ni}$ ratios show about $50 \%$ decrease after $10 \mathrm{~nm}$ sputtering of the fracture surface, thereby suggesting that surface concentrations of both sulphur and oxygen tend to reduce. However, with further sputtering, the rate of decrease in concentration is found to be much less. In the case of alloy 4, as shown in Fig 6, the rate of decrease in the concentrations of oxygen and sulphur is observed to be much faster. It shows a decrease of more than $75 \%$ after $10 \mathrm{~nm}$ sputtering and beyond $20 \mathrm{~nm}$ sputtering the concentration remains virtually unchanged.

The sputtering profiles of alloy 1 have clearly confirmed the presence of sulphur at the fractured surface. This could be due to either the formation of carbosulphide of titanium or segregation of sulphur at the surface. Since in both the alloys, titanium was also found to be present in these areas along with carbon, it is believed that these are titanium carbosulphides. Occurrence of $\mathrm{Ti}_{2} \mathrm{CS}$ has also been shown in maraging steels by Ball [16] who after detailed X-ray diffraction studies, has suggested that in an alloy containing minor amounts of titanium, carbon and sulphur, titanium carbide will not form without the formation of titanium carbosulphide. Like maraging steels, alloy 718 also contains fairly low carbon but its titanium content is much higher. Therefore, probability for the formation of titanium carbosulphide is also much higher in alloy 718 and this could be detrimental to the high temperature properties. A minor addition of cerium can substantially bring down the level of sulphur during the melt refining stage itself, thereby minimizing the formation of $\mathrm{Ti}_{2} \mathrm{CS}$ and segregation of sulphur and this is what we have observed in the cerium-modified alloy 4. 


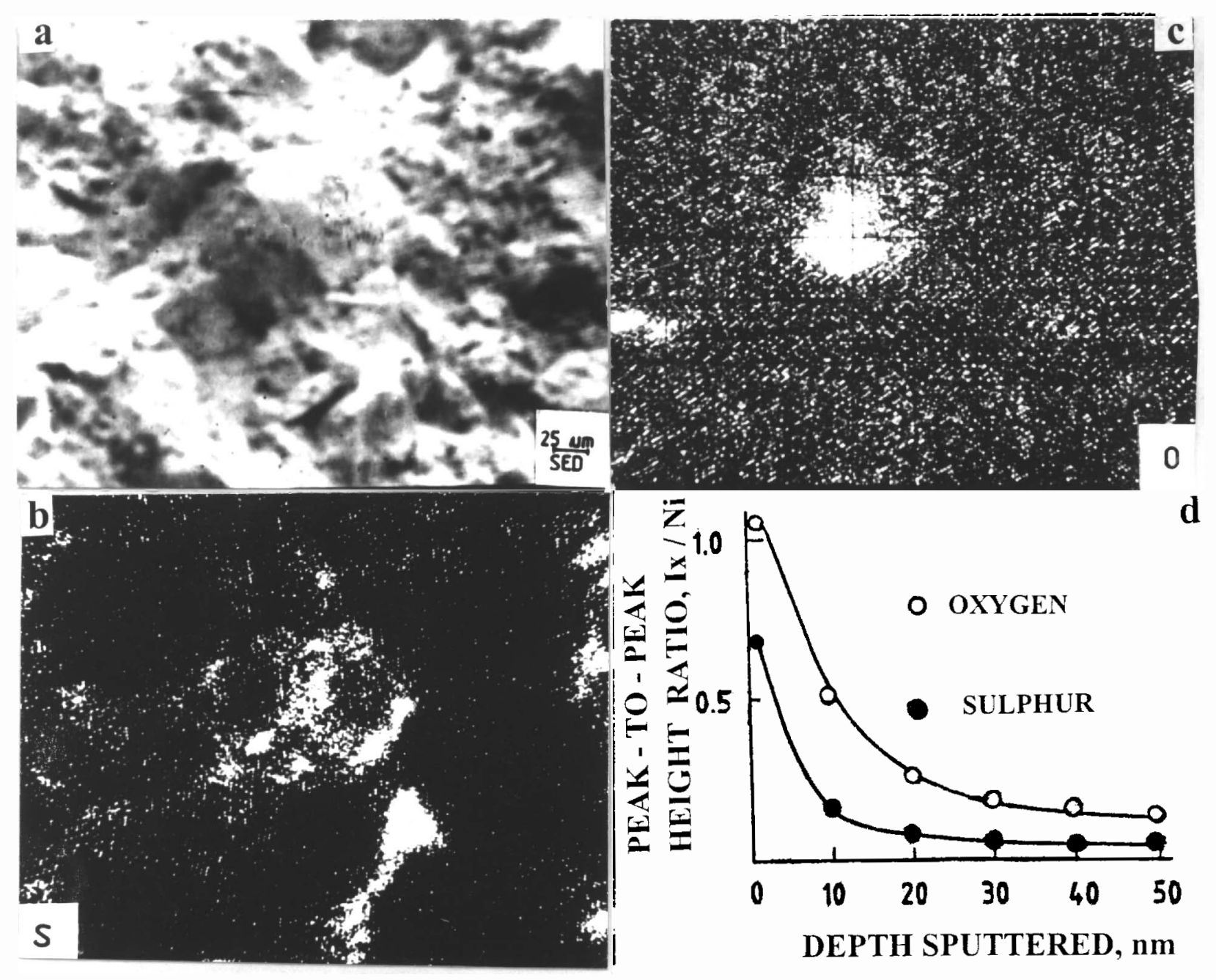

Fig. 5 Auger microprobe analysis for alloy 1 showing (a) fracture surface (b) Auger graph for sulphur and (c) Auger graph for oxygen and (d) a graph between peak to peak height ratios for oxygen and sulphur against the sputtered depths. 


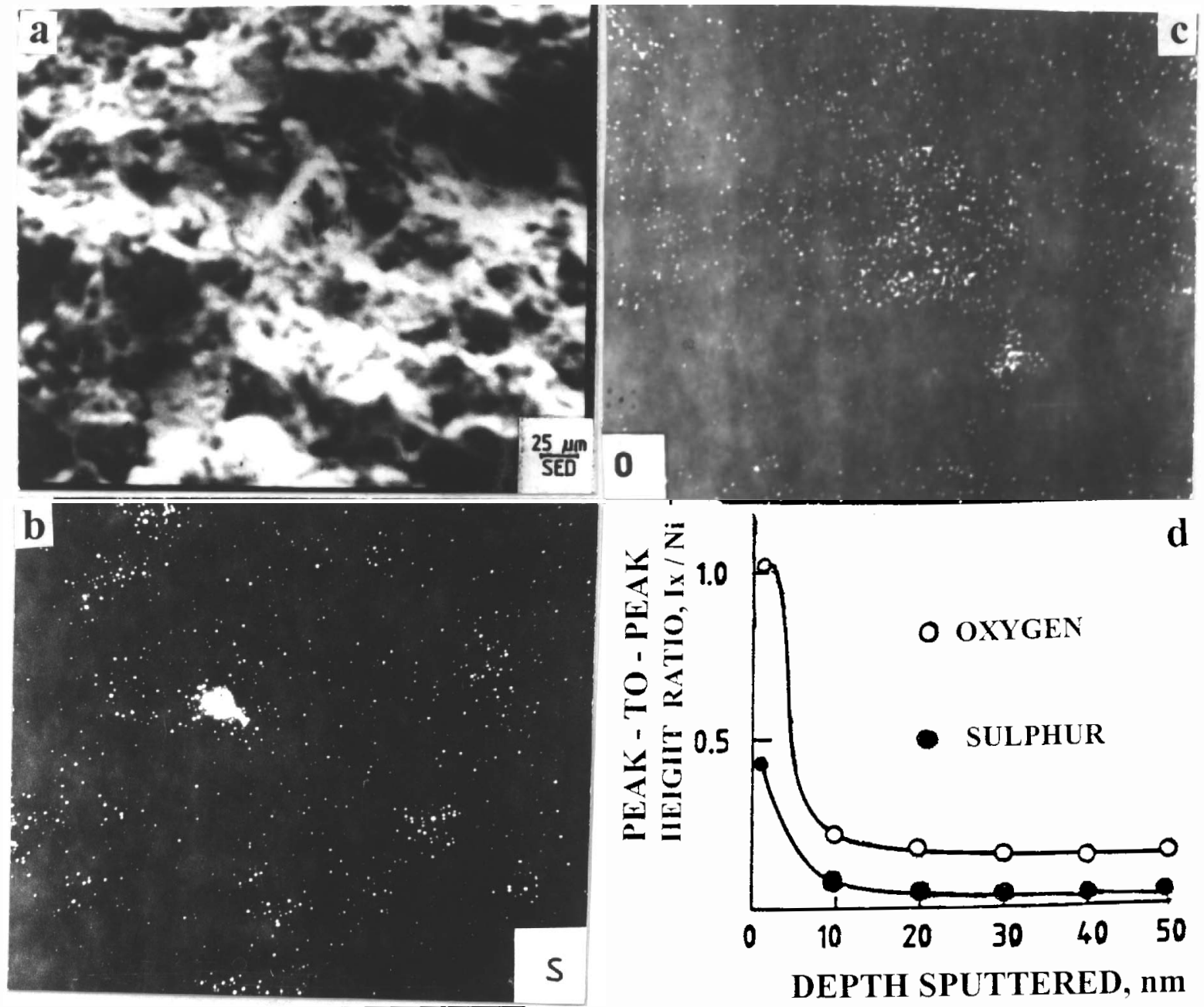

Fig, 6 Auger microprobe analysis for alloy 4 (cerium modified) showing (a) fracture surface (b) Auger graph for sulphur (c) Auger graph for oxygen and (d) a graph between peak to peak height ratios for oxygen and sulphur against the sputtered depths. 


\section{Conclusions}

1. Addition of cobalt either in place of nickel or iron has not been found to produce any noticeable effect on the room temperature or high temperature properties of alloy 718 .

2. Addition of cerium in controlled proportions is beneficial and leads to a significant improvement in the high temperature properties of alloys 718 .

\section{Acknowledgements}

Thanks are due to various colleagues of the laboratory for their help in conducting microstructural examination and property evaluation. We are grateful to Dr. D. Banerjee, Director, DMRL for permission to publish this work.

\section{References}

1. E. A. Loria, 'Recent Developments in the Progress of Superalloy 718', J.Metals, 44 (1992), 33-36.

2. E. A. Loria, 'The Status and Prospects of Alloy 718', J. Metals, 40 (1988), 30-36

3. Stephen, D.Antolovich, Superalloy 718-Metallurgy and Applications, E.A.Loria ed., The Minerals, Metals and Materials Society, 1989,

4. J. P. Collier, S. H. Wong, J.C. Phillips and J.K. Tien, 'The Effect of Varying Al, $\mathrm{Ti}$ and $\mathrm{Nb}$ content on the phase stability of Inconel 718', Met. Trans, 19A(1988) $1657-1666$

5. E. E. Brown and D. R. Muzyka, "Nickel-Iron Alloys" in Superalloys II, ed., C. T. Sims, N. S. Stoloff and W. C. Hagel, John, Willey and Sons, New York, 1987, 168-187.

6. J.F. Radavich and S.Tien, Proc. Vac. Metal Conf. AVS-I \& SS (1986), 103-106.

7. G.L.R. Durber, CL Jones and AJ Dykes, "VIM \& ESR Alloy 718-An Assessment of Chemistry control, alloy cleanliness and mechanical properties', Superalloys 1984, ed., M.Gell et al, TMS, 1984, 433-441.

8. R.T. Holt and W. Wallace, 'Impurities and Trace Elements, International Metals Reviews, 1976, 1-23

9. D. R. Muzyka and C.R. Whitney, US Patent No. 3575734, 20 April, 1971.

10. J. M. Moyer, 'Extra low carbon Alloy 718', Superalloy 1984, M.Gell et al, eds., TMS 1984, 443-454

11. J. Heslop, cobalt, 24 (1964) 128-137

12. D. Coutsouradis and L. Habraken, J. Metal , 35 (1983) 40-47 
13. Robert N. Jarret, John P. Collier and John K. Tien, 'Effect of cobalt on the Hot workability of Nickel base superalloys' Superalloys 1984, ed., M.Gell et al., TMS, 455-466.

14. I. Kirman and D.H. Warrington, 'The precipitation of $\mathrm{Ni}_{3} \mathrm{Nb}$ phases in a $\mathrm{Ni}-\mathrm{Fe}-$ Cr-Nb alloy, Met Trans., 5A(1970), 2667-2775

15. M. Sunderaman, P. Mukhyopadhaya and S. Banerjee, 'Some Aspects of the precipitation of Meta stable Intermetallic phases in Inconel 718, Met Trans. 23A (1992), 2015-2028

16. C. J. Ball. "X-ray powder diffraction patterns of titanium carbosulphide and titanium sulphide, Met. Sc., 18(1984), 577-579. 